\title{
PERCEPÇÕES HISTÓRICAS SOBRE O LAZER E A SOCIABILIDADE NA BAHIA (1850 - 1900)
}

Recebido em: 10/01/2018

Aceito em: 16/08/2018

\author{
Lizandra de Souza Limal \\ Rede Municipal de Educação de Alagoinhas - BA \\ Alagoinhas - BA - Brasil \\ Coriolano P. da Rocha Junior ${ }^{2}$ \\ Universidade Federal da Bahia (UFBA) \\ Salvador - BA - Brasil
}

\begin{abstract}
RESUMO: Este texto aborda a construção do lazer e o desenvolvimento da sociabilidade na Bahia no final do século XIX. Este estudo tem como problema norteador: Qual o processo histórico que fundou a estrutura das práticas de lazer e de sociabilidade na cidade de Alagoinhas-BA? Salientamos que nesse período a ideia de lazer estava em consolidação. Nosso objetivo foi entender como as práticas de lazer e sociabilidade se consolidou na cidade. Baseada na metodologia da Nova História Cultural, temos como recorte o período compreendido entre 1850 e 1900 . Como fontes vimos periódicos da época e produções literárias que abordam o período em questão. Vemos a partir desta busca que as práticas de lazer e sociabilidade do século XIX se estruturaram em Alagoinhas a partir influência dos imigrantes que também influenciaram na estrutura urbana, deixando sua marca nos espaços públicos e na cultura da cidade.
\end{abstract}

PALAVRAS CHAVE: História. Sociabilidade. Atividades de Lazer.

\section{HISTORICAL PERCEPTIONS ON LEISURE AND SOCIABILITY IN BAHIA (1850 - 1900)}

ABSTRACT: This text boards the construction of leisure and the development of sociability in Bahia in the late nineteenth century. This study has as a guiding problem: What is the historical process that founded the structure of leisure and sociability practices in the city of Alagoinhas-BA? We emphasize that during this period the idea of leisure was in consolidation. Our objective was to understand how the practices of

\footnotetext{
1 Mestra em Educação (UFBA); Licenciada em Educação Física (FSBA); Professora da Rede Municipal de Ensino de Alagoinhas - Bahia.

${ }^{2}$ Pós-doutorado em História pela Universidade de Lisboa; Doutor em História pela Universidade Federal do Rio de Janeiro; Mestre em Educação Física pela Universidade Gama Filho; Licenciatura em Educação Física pela Universidade do Estado do Rio de Janeiro; Professor da Graduação e do Programa de Pósgraduação em Educação da Faculdade de Educação da Universidade Federal da Bahia.
} 
leisure and sociability were consolidated in the city. Based on the methodology of the New Cultural History, we cut as the period between 1850 and 1900. As sources we have seen periodicals of the time and literary productions that approach the period in question. We see from this search that the practices of leisure and sociability of the nineteenth century were structured in Alagoinhas from the influence of the immigrants who also influenced the urban structure, leaving its mark in the public spaces and the culture of the city.

KEYWORDS: History. Sociability. Leisure Activities.

\section{Introdução}

Este estudo esboça nuances sobre a estruturação do lazer na Bahia a partir do desenvolvimento da sociabilidade na cidade de Alagoinhas, interior do estado da Bahia no período compreendido entre a transição do modelo monárquico para o republicano. A cidade escolhida tem sua relevância devido sua história estar atrelada a implantação da malha ferroviária no país, recebendo, por conta desse fato, diversos estrangeiros, muitos de nacionalidade italiana, destinados á trabalhar nas atividades da ferrovia.

Essa demanda de crescimento e modernidade, que atingia todo o país desde a chegada da família real em 1808, trouxe à pacata Freguesia de Santo Antônio das Lagoinhas - nome do povoado que viria a se tornar a cidade de Alagoinhas - novos ideais dentre eles sociabilidade, entretenimento e divertimento. Mesmo ainda sem se apropriar publicamente desses termos, vemos nesse momento as primeiras ações de lazer desenvolvidas na localidade.

Dumazedier (2014) aponta o lazer como um fenômeno capaz de influenciar diversos espaços da nossa sociedade, como as relações que estabelecemos com o ambiente a nossa volta. A este fenômeno emprega-se um conjunto de atividades opostas às necessidades e obrigações da vida cotidiana, que possuem como princípio central a liberação e o prazer, categorizando-se em três funções mais específicas: o descanso; o divertimento, recreação e entretenimento; e o desenvolvimento. 
Lizandra de Souza Lima e Percepções Históricas sobre o Lazer e a Sociabilidade na Bahia (1850-1900) Coriolano P. da Rocha Junior

A partir das possíveis definições, entenderemos para este estudo, o lazer como uma prática cultural humana, vivida no tempo disponível, que reflete interesses variados representados em diversas manifestações, atrelados a livre escolha e a busca pelas sensações de descanso, divertimento, recreação e entretenimento, possibilitando nas suas vivências, situações de desenvolvimento humano.

Para efeito desse estudo, podemos identificar cultura como sendo todas as atividades da vida cotidiana, reais ou fictícias, que podem construir a base de uma vida cultural e ainda, ser suporte de um desenvolvimento neste setor.

Como prática cultural, o lazer compõe e atua na cultura da sociedade e nesse sentido Dumazedier (2014) expressa à linha tênue que há entre a produção cultural, sua ligação com o lazer e o desenvolvimento humano e social expondo dois exemplos de tratamento à cultura: a cultura de massa, em um padrão estético acrítico, pré-fabricado, e a edificação cultural, em uma ação composta e feita para as pessoas.

Nesse aspecto, temos na cultura de massa a particularidade de ser pré-moldada. Suas características principais chegam pré-determinadas e a mídia, junto a outros meios hegemônicos, cuidam de sua disseminação.

Outra compreensão possível de cultura popular, que se relaciona diretamente com a edificação cultural, numa forma simples de comparação, aborda em conceito, seu desenvolvimento segundo as características do povo que a vivencia. Trata-se de um conteúdo elaborado por um povo sobre suas próprias práticas e por isso, capaz de assumir significados variados, em diálogo com as diversas formas de vivência cotidiana, influenciando e sendo influenciada por aqueles que a vivem.

Atualmente, as formas de cultura têm sido mescladas. Aspectos como a globalização e a dita ação de apropriação da ideia de modernidade tem incidido 
Lizandra de Souza Lima e Percepções Históricas sobre o Lazer e a Sociabilidade na Bahia (1850-1900) Coriolano P. da Rocha Junior

diretamente na construção da cultura popular, o que tem realçado o movimento da cultura de massa (MORIN, 1997).

Esse aglomerado de culturas e as tensões existentes entre essas facetas são evidenciadas por Melo (2012), como um dos aspectos de contradição necessários para a existência do lazer. Expondo a ideia de que ao mesmo tempo em que essa cultura fornece um padrão comportamental, ela também fornece elementos para a transgressão e resistência a esse mesmo padrão. Todavia, esse processo transgressor se moldaria sob a prática educativa, a existir no espaço-tempo de ação cultural, que pode ser o lazer.

Dessa forma, dentre as funções já expostas, é possível identificar no lazer o potencial de propagar, construir e reformular a cultura popular sob a ação de uma práxis educativa, ainda que, por vezes, não seja possível constatar a quem essa ação pedagógica irá servir, se a um padrão hegemônico ou contra hegemônico.

Este processo ocorre em um ambiente que precisa ser visualizado como um todo, não apenas no seu conceito social, como também no estrutural, pois a construção do lazer, na sua magnitude, perpassa diversos campos da sociedade como sua estrutura urbana e econômica, por exemplo.

O processo de urbanização incide diretamente na disposição do fenômeno do lazer na sociedade e é notório que a estruturação das cidades é capaz de influenciar, em alguma medida, a expectativa da população com o seu tempo livre, além de estimular novos desejos e expectativas para o mesmo, ajudando a consolidar novas representações e novos hábitos (GONÇALVES; MELO 2009).

Percebendo como locais socioculturais, todo espaço destinado ao público disponível numa comunidade, vemos que a estruturação do lazer numa sociedade é, em grande parte, determinada a partir do seu ordenamento espacial e geográfico, assim 
Lizandra de Souza Lima e Percepções Históricas sobre o Lazer e a Sociabilidade na Bahia (1850-1900) Coriolano P. da Rocha Junior

como também as questões de acesso e mobilidade incidem nesse determinismo. Além dessas observações, Freire e Sartório (2015) ainda apontam que quando uma cidade não conta com espaços públicos próprios para a prática do lazer, o aproveitamento da vida cotidiana acaba por ocorrer em ambientes livres, tais como ruas, calçadas e praças, por exemplo. No caso, qualquer espaço que propicie o encontro e a interação social passa a se configurar como um recinto possível do lazer a partir da sociabilidade.

Dortier (2010) associa a sociabilidade, com a ideia de estabelecer relações sociais de forma eletiva, por afinidade, sem que esta ofereça de fato uma função utilitária. Dessa forma, ao falarmos de prática de sociabilidade, estamos nos debruçando em torno de toda relação interpessoal, considerando que sua prática se reflete nas percepções do indivíduo em torno do seu conhecimento e compreensão, em diversas áreas.

Essa reflexão nos leva a reconhecer, que mesmo esta relação não se articulando em torno de uma função predeterminada, ela incide na cultura dos sujeitos que a envolvem, reafirmando ou reestruturando o entendimento sobre algo ou um conhecimento específico compartilhado nesse contato.

Analisando de modo ampliado a história, temos no lazer variadas roupagens durante a evolução social da humanidade. Vemos nessa sociabilidade o que Cardozo (2014) aponta, como a construção do conhecimento relacionado a essa área de estudo, tendências hegemônicas do: "lazer resíduo (consumo), lazer idealizado, lazer higienista, lazer como experiência, lazer como crítica do trabalho, lazer negado e lazer educativo" (2014, p. 21).

O autor ainda defende que durante os séculos XIX e XX, mesmo com outra representação, predominavam ideias de um lazer idealizado, onde este era visto como 
Lizandra de Souza Lima e Percepções Históricas sobre o Lazer e a Sociabilidade na Bahia (1850-1900) Coriolano P. da Rocha Junior

"privilégio humano por excelência para as artes e a filosofia" (CARDOZO, 2014, p. 18). Hoje, no contexto moderno "se apresenta como uma alternativa ao consumo mercantilizado" (CARDOZO, 2014, p. 18). Nessa perspectiva, pairava sobre o lazer uma ideologia de "luxo", onde a sua prática não se apresentava a todos que a bem quisessem.

Dado isso, reconhecendo a pesquisa histórica como não detentora de toda verdade, porém capaz de indicar facetas e caminhos para uma melhor analise da sociedade, este estudo estrutura na perspectiva histórica um caminho, dentre tantos outros, que possibilita vislumbrar a construção dos espaços de lazer na cidade de Alagoinhas e a representação cultural das práticas sociais.

No intuito de uma aproximação, a priori, torna-se interessante entender que Alagoinhas é uma localidade que nasceu a partir da estadia de tropeiros durante o percurso das viagens para transporte de gado, pela Estrada das Boiadas que se estendia da Bahia ao Piauí (SANTANA, 2015).

Atualmente, Alagoinhas é um polo industrial, comercial e educacional, sendo considerada uma cidade central para sua região. A ela se destinam indivíduos das cidades circunvizinhas em busca de oportunidades de ensino e trabalho. Esse processo se mostra presente durante todo percurso histórico da cidade, desde os que vieram para trabalhar na construção das ferrovias e depois a rodovia, até os que se destinaram às instituições de ensino, como os que aqui chegaram juntamente com o Campus II da Universidade do Estado da Bahia (UNEB). Alagoinhas é um núcleo urbano regional que se estabeleceu como um centro intermediário entre a região metropolitana de Salvador e a área do Litoral Norte (ARAÚJO, 2010). 
Lizandra de Souza Lima e Percepções Históricas sobre o Lazer e a Sociabilidade na Bahia (1850-1900) Coriolano P. da Rocha Junior

\section{Metodologia}

Consciente que uma pesquisa necessita ter apenas um problema norteador, o presente estudo emerge da seguinte questão: Qual o processo histórico que fundou a estruturação das práticas de lazer e de sociabilidade na cidade de Alagoinhas-BA?

É importante evidenciar que no contexto histórico onde esta pesquisa visita, a ideia de lazer não se apresentava consolidada como o padrão atual. Estamos falando de um processo de construção desse espaço-tempo, assim como da elaboração de todos os elementos que o ronda. Afinal, o desenvolvimento do termo lazer está diretamente ligado, no âmbito mundial, aos avanços econômicos e dos ganhos de direitos.

A partir de nossa questão de estudo, temos como objetivo geral, compreender como as práticas de lazer e sociabilidade se estruturaram na cidade; e como objetivos específicos: Apontar e analisar as práticas culturais e suas representações para o lazer e sociabilidade que ocorriam à época.

Por se tratar de práticas culturais, lidaremos com a Nova História Cultural como método de pesquisa, pois como apresentado por Melo, et al. (2013) quando a produção cultural nos conduz a análises que não findam na prática apenas, mas perpassam em ideologias dominantes e hegemônicas, devemos ter por base a cultura. Um dos tocantes da História Cultural é a preocupação com a representatividade, os símbolos e as interações com o objeto de pesquisa. Nessa linha analítica, o foco não está exclusivamente em como o objeto se delineia, mas também em tudo que se relaciona com o mesmo.

Neste artigo, usamos como recorte temporal o período definido entre 1871, a partir do marco da inauguração da primeira estação de passageiros e 1900, com a inauguração da Estação de Prolongamento da linha férrea, momento que marca pois, a 
entrega da nova estação viria a reafirmar a importância da estrada de ferro para a cidade, devido ter, dentre muitas funções, galpões de armazenamento e estoque dos produtos que trafegavam pelo trem possibilitando a comercialização de novos produtos e consequentemente a oferta de novos serviços.

Como fontes, temos por base os dados coletados nos periódicos que circulavam na época e produções literárias e acadêmicas acerca do nosso objeto no período. Para escolha do material levamos em consideração alguns critérios: dissertações e teses que abordassem a história da cidade dentro do mesmo recorte temporal, periódicos que foram veiculados na época, e títulos literários que delineiam o processo de estruturação da cidade.

Nesse intuito partimos na busca de dados e indícios das práticas culturais, por iniciativa privada ou pública, existentes no processo de construção da ideia de urbanização e modernidade na cidade de Alagoinhas, levantando assim as ações ocorridas na época e um padrão de características que nos auxiliam a problematizar as práticas de lazer, dentro do recorte temporal determinado.

Damos destaques às fontes localizadas na Hemeroteca Digital da Biblioteca Nacional onde estão disponíveis em versão online edições de jornais que circulavam entre 1870 e 1889. Contamos também com os livros, em fotocopia, disponibilizados pela Biblioteca Pública Municipal Maria Feijó, em Alagoinhas - Bahia. Além do material acessível em sua versão impressa e original, na Biblioteca do Instituto Histórico e Geográfico da Bahia, localizado em Salvador, capital da Bahia. 
Lizandra de Souza Lima e Percepções Históricas sobre o Lazer e a Sociabilidade na Bahia (1850-1900) Coriolano P. da Rocha Junior

\section{As Práticas de Sociabilidade e Lazer na Formação de Alagoinhas}

Revisitando a construção da cidade de Alagoinhas, identificamos que a mesma começou a se estruturar a partir de sua emancipação da Villa de Inhambupe, condição que foi oficializada em 1853. Todavia, foi só com a chegada da ferrovia, em 1863, que a sede da cidade começou a ser transferida da antiga vila (conhecida atualmente pelo bairro de Alagoinhas - Velha) para mais próximo dos trilhos. Nesse momento vemos um dos processos mais conflituoso e determinante no tocante do seu ordenamento e apropriação do espaço pela comunidade: A mudança da sede urbana. Esta ação foi oficializada em 1868, com a elevação do lugarejo à Villa de Alagoinhas. (BARROS, 1979)

$\mathrm{Na}$ antiga sede, antes da transferência havia um ambiente social furtivo propiciado pela localização da nova edificação para a igreja do povoado onde "No entorno dessa nova matriz foram feitas construções residenciais e ali tropeiros e viajantes realizavam feiras, desenvolvendo um próspero comércio" (SANTOS, 2009, p.3).

Sobre essas feiras temos a maior quantidade de registros relacionados às práticas sociais que ocorriam nessa comunidade. Tendo por base documentos que apontam normas de convivência para Villa de Santo Antônio de Alagoinhas, Lima (2010) levanta alguns indícios dessas práticas:

Pois, o que se proíbe é o que se pratica, e pelo exame do que se proíbe podem-se perceber, portanto, práticas em uso em uma determinada sociedade. Assim é que o fato de uma norma ter proibido, por exemplo, apresentação de danças, vendas de bilhetes sem a autorização da Câmara, revela que isso se dava livremente na vila; (...) (LIMA, 2010, p.34).

Sabe-se que as práticas sociais de uma comunidade são a representação da cultura do povo que a compõe. No referido período, este povo era composto por 
Lizandra de Souza Lima e Percepções Históricas sobre o Lazer e a Sociabilidade na Bahia (1850-1900) Coriolano P. da Rocha Junior

“boiadeiros, negros fugidos que partiam em busca dos quilombos, índios aldeiados, [...] além de tropeiros e viajantes que comercializavam mercadorias" (ALAGOINHAS, 1996, p.8). Há registros também que estas regiões eram povoadas por gente "geralmente mestiça e derivada do cruzamento de portuguezes, caboclos e africanos, entrando os primeiros por uma pequena parte" (BULHÕES, 1874, p.33).

A crescente ascensão da Villa fez com que o padre José Rodrigues Pontes iniciasse uma obra de reforma da capela que acabou não sendo concluída ${ }^{3}$. O abandono da obra, dentre diversos motivos de ordem financeira e também política, ocorreu dado o deslocamento da sede da vila para a localidade onde a linha férrea foi instalada, à aproximadamente $3 \mathrm{~km}$ da antiga sede (LIMA, 2010 e BARROS, 1979).

De maneira abrupta, a área que após a transferência da sede, passou a ser chamada de Alagoinhas - Velha, saiu da realidade de vivências sociais arrojadas, tradicionais dos momentos de feira que movimentavam noite e dia, para um cenário de abandono, com vias públicas mal cuidadas, sem limpeza ou cuidados similares (LIMA, 2010).

Esse deslocamento, além de ser determinante para o crescimento da vila, foi carro chefe para a chegada de novos ideais de sociedade para todos.

Como as localidades não eram próximas, o município passava a ter um momento de ruptura em seus padrões sociais. As feiras e todo mercado que rondava a antiga vila foram transferidas para próximo da nova sede municipal, o que provocou revolta na população, que já estava instalada na antiga região (BARROS, 1979).

Enquanto isso o país, no mesmo período, ganhava uma nova roupagem econômica, com o advento da abolição da escravatura, da organização da República, um

\footnotetext{
${ }^{3}$ A obra inacabada da Igreja de Santo Antônio permanece de pé até os dias atuais, embora algumas partes já tenham caído devido à ação do tempo.
} 
Lizandra de Souza Lima e Percepções Históricas sobre o Lazer e a Sociabilidade na Bahia (1850-1900) Coriolano P. da Rocha Junior

maior investimento de capital estrangeiro, dentre outros aspectos. Sobre isso Bolelli (2013) sinaliza que o país do final do século XIX ainda apresentava uma economia baseada na agroindústria e o processo de implantação do trabalho assalariado foi percursor de uma serie de desequilíbrios econômicos favorecendo a injeção de investimentos das economias centrais mundiais aumentando o fluxo de capital, principalmente inglês, no país. Estes investimentos traziam para a localidade o movimento de modernização e desenvolvimento tecnológico que estas economias vivenciavam.

Esse ciclo de transformações ocorrido no país foi acompanhado de perto por Alagoinhas, que teve na ferrovia de capital inglês e administração franco-belga (Ferrovia Bahia and San Francisco Railway), a ação impulsionadora de suas mudanças. Em 1868 se deu a inauguração da ferrovia, e a primeira estação de passageiros foi inaugurada em 1871. Depois de uma pausa nas obras, devido a conflitos de interesses políticos, uma estação de prolongamento foi inaugurada em 1900. Ambas as estações carregam em sua construção as representações da influência inglesa na sua arquitetura (LIMA, 2010).

No contexto da construção da estrada de ferro, ampliava-se o entendimento do que é ser uma cidade urbana para os moradores da região. As construções de casas, a estrutura das ruas, as normatizações à feira e seus produtos, investimentos no comércio e afins, apontou para uma nova Alagoinhas, agora, uma cidade que visava o progresso, seguindo os anseios das novas direções que o Brasil tomara frente à formulação de sua república.

Nesse propósito, com a ajuda do engenheiro Trajano da Silva Rego foi desenvolvido um projeto de planejamento urbano entre 1868 e 1871 . O documento tinha 
Lizandra de Souza Lima e Percepções Históricas sobre o Lazer e a Sociabilidade na Bahia (1850-1900) Coriolano P. da Rocha Junior

por objetivo ordenar o desenvolvimento físico da Vila e vislumbrava a abertura de ruas e travessas, assim como a construção de praças (LIMA, 2010).

Gonçalves e Melo (2009) relacionam o desenvolvimento das cidades com o crescimento do fenômeno lazer e de fato, isso se confirma na história, em contrapartida, para Alagoinhas, uma cidade recém-formada, ainda havia um logo processo de estruturação pela frente.

Nesse momento já podemos observar que no final do século XIX, a estrada de ferro já apresentava a repercussão da sua presença em diversas frentes. Na estrutura física da cidade, teve a construção de casas e oficinas de manutenção do serviço, além de fomentar uma necessidade de ordenação do espaço físico que a rondava. Na economia local proporcionou vagas de emprego direta e indiretamente ligadas à estrada. Pelo relato de Joanita Santos, autora do livro de memorias Traços de Ontem, a linha férrea ainda se mostrava como um meio de lazer ao dizer que "os alagoinhenses viajavam para a Capital para resolver negócios, fazer compras, ou mesmo para assistir os filmes" (SANTOS, 1987, p. 23).

Embora ainda pobre e com sua receita baseada em pequenas produções agrícolas, tínhamos uma cidade que "começou a viajar, a se comunicar, a viver melhor, comportamentos que elevaram a mentalidade do povo, refletindo, sobremaneira, na vida sociocultural do lugar (SANTOS, 1987, p. 29)".

Esse relato nos permite dizer que a linha inglesa era de fato um meio viabilizador para o acesso a novos padrões de entretenimento e de sociabilidade, que anteriormente esta comunidade não possuía.

Dada essa demanda estrutural, a cidade passou a buscar, na figura do planejamento urbanístico, uma nova reorganização visando como parte principal das 
Lizandra de Souza Lima e Percepções Históricas sobre o Lazer e a Sociabilidade na Bahia (1850-1900) Coriolano P. da Rocha Junior

mudanças: a Casa da Câmara, o barracão da estrada de ferro, o mercado e a abertura das principais ruas, travessas e praças. Dentre as características desse projeto, vemos que: “as ruas são retas e espaçosas e um espaço público que objetivava a circulação de homens e mercadorias - Praça do Comércio - que facilitaria contatos ágeis, conversas curtas e boa movimentação" (LIMA, 2010, p. 56).

Como decorrência dessas modificações, a vila ganhou um dinamismo nas atividades próprias da vida social, como podemos observar, por exemplo, em uma reportagem do jornal $A$ verdade de julho de 1877, que descreve um espetáculo que ocorrera em um teatro da vila, organizado pela família Granado.

A execução de espetáculos de teatro fazia parte da vida social da vila. Na edição de 11 de fevereiro do mesmo ano foi reportado uma peça beneficente, em prol da liberdade de uma escrava, organizada pela Sociedade 7 de setembro, que apesar da causa, não teve uma boa adesão de acordo com o periódico. Nessa reportagem foi feito o anúncio de outro espetáculo que seria realizado na semana seguinte, mostrando assim que o teatro de fato fazia parte das práticas de lazer da época.

Além deste, o periódico explicita que, embora de forma sutil, a vila passava a contar com novos hábitos culturais. A partir de uma propaganda veiculada no jornal A Verdade, de 31 de março de 1878, é possível identificar que a vila passava a ter nesse momento, por exemplo, a reestruturação de pousadas para padrões hoteleiros que contavam até com o serviço de restaurante.

Esses locais foram representações de mudanças, não apenas nos padrões econômicos, mas também sociais. Lima (2010, p.62) afirma, que afinal "a chegada de pessoas que vinham a Alagoinhas, seja para negociar ou de passagem para o interior, exigiu uma melhoria nos serviços" e também repercutiu nas práticas sociais do povo. 
Lizandra de Souza Lima e Percepções Históricas sobre o Lazer e a Sociabilidade na Bahia (1850-1900) Coriolano P. da Rocha Junior

Joanita Santos nos mostra mais exemplos de como essa comunicação com a capital, e com os que de lá chegavam através do trem, repercutiam no cenário das práticas sociais locais:

\begin{abstract}
Antigamente, havia em Salvador um célebre barzinho chamado 'Café das Meninas'. Em Alagoinhas, havia um similar: 'Salão Moderno', (...). Fernando, o mais velho, que residia na Capital, sempre aparecia, alegrando o ambiente do Salão, tocando piano. Sim! Tinha um piano que ficava perto das mesinhas onde eram servidos cafezinhos e aperitivos. Era ali o ponto de encontro para discussões políticas ou palestras informais entre amigos (SANTOS, 1987, p. 35).
\end{abstract}

Lidar com um aumento de padrões e valores da população requer não apenas interesse social, mas também investimento estrutural por parte dos governantes. A cidade do final do século XIX não contava com infraestrutura básica como saneamento, iluminação adequada ou transporte público, por mais que houve uma aspiração para tal. Com a elevação à condição de cidade adquirida na década de 1880 , a postura de assumir a estética urbana passava a viabilizar as mudanças necessárias para essa demanda (LIMA, 2010).

Para entender o que essa mudança implicou, Dortier (2010) nos apresenta que a ideia de cidade passa pela noção de produção e comércio. Trata-se de quando "Num mesmo local, começam a erguer-se (...) grandes avenidas com suas 'grandes lojas', os parques, os cafés, os teatros, os museus... Constitui-se uma sociabilidade urbana (p.71)”. Falamos assim de um lugar que vive o "individualismo, das relações impessoais, das novidades, das permutas racionais pelo dinheiro e pelo comercio (DORTIER, 2010, p. 71)".

A intenção aqui é entender que ao entrarmos no tocante da estrutura da cidade, não o fazemos apenas no plano das estruturas físicas, mas também no contexto de padrões comportamentais e relacionais. Nesse contexto a sociedade que compunham a 
Lizandra de Souza Lima e Percepções Históricas sobre o Lazer e a Sociabilidade na Bahia (1850-1900) Coriolano P. da Rocha Junior

nova sede da vida mostra-se ativa na adesão a essa nova concepção idealizada para a Alagoinhas dos anos finais do século XIX.

Nesse período se via um crescimento no comércio da cidade. No geral eram "vinte e sete negociantes dedicados à venda de tecidos, miudezas, ferragens, louças e calçados (LIMA, 2010, p.81)". Muitos dos empreendimentos recém-inaugurados contavam com iniciativa e influência dos imigrantes vindos de diversas localidades do globo. No total, se viram residentes “em 1890, em Alagoinhas, vivia vinte e dois indivíduos de outras nacionalidades. Desses se registraram um norte americano, dois britânicos, dezesseis italianos, um português e dois espanhóis (LIMA, 2010 p. 82)”.

Em seus negócios eram ofertados aos alagoinhenses produtos importados como licores e vinhos, além de vestimentas e assessórios de beleza e estética, tanto pessoal quanto de casa. Isto influenciava não apenas na moda, como na mentalidade e valores de uma sociedade que começava a se apropriar de ideais cosmopolitas, contudo ainda vivia uma realidade um tanto rural (LIMA, 2010).

A cidade vivia um novo tempo, acompanhando o movimento nacional de adesão às ideias republicanas. Estávamos agora no inicio da Primeira República, o movimento abolicionista ganhara força e se consolidava e vivíamos um momento histórico guardado nos ideais de progresso e, como carregamos na frase do símbolo patriota da bandeira do país, necessitava de ordem.

Novos ideais, aproximações com a cultura imigrante, a nova relação com o tempo, entre outros padrões de consumo e comércio conduziu o poder público a direcionar boa parte de sua receita e verbas para a organização do centro urbano da cidade, no intuito de atender as necessidades de um povo que agora se via nos anseios da vida urbana: a necessidade de espaços de sociabilidade. 
Lizandra de Souza Lima e Percepções Históricas sobre o Lazer e a Sociabilidade na Bahia (1850-1900) Coriolano P. da Rocha Junior

\section{Os Espaços de Sociabilidade em Alagoinhas na Transição do Século}

As ruas contavam com a iluminação de candeeiros apenas, serviço iniciado no ano de 1878. Não havia calçamento ou uma estrutura que permitisse uma boa circulação pelas vias públicas nesse período. Se a temporada fosse chuvosa, a situação ainda se agravava. (LIMA, 2010)

Ainda assim, algumas práticas sociais eram realizadas como, por exemplo, a tradicional feira. Definitivamente esse espaço mostrava-se como um ambiente com alta disponibilidade à prática social como vemos a seguir:

Não conheço instituição mais democrática do que a feira, onde se encontram indivíduos de todas as cores, gente de todas as posições, desde o capadócio até o doutor (...) questionando alto, conversando amigavelmente ou contando casos alegres e desopilantes (BARREIRA, 1902, p.201).

O espaço da feira era ocupado por pessoas de toda região. Desde os trabalhadores da feira que "desde muito cedo começam a affluir de todas as ruas e estradas centenas e centenas de indivíduos, homens, mulheres e creanças (BARREIRA, 1902, p. 199)", até o público que dela iria usufruir como os "habitantes da cidade, chefes de família que saem para labuta diária, senhoras acompanhadas por criados e amas de côfo enfiado no braço, ou conduzindo balaios..." (BARREIRA, 1902, p. 200).

Mesmo o autor entendendo que este espaço se apresentava democrático, vemos em seus relatos que há uma distinção entre os que estavam ali. As classes e grupos sociais mostram-se bem delineados e ficava coerente a visualização de que esta democracia se apresentava apenas no aspecto da presença física. Já que a interação mais constante que se estabeleceu ali tinha conotação comercial. 
Apesar dessas contradições, o sábado de feira era o momento mais rico de práticas sociais em ambiente público do final de semana. A mesma animação não era vista pelas ruas da cidade no dia posterior a feira:

O domingo, porém, contrasta singularmente com a véspera, é um dia morto, insípido e sem movimento algum, o que se explica pela falta completa de distrações e divertimento e, em parte, pela pouca sociabilidade da população, que em geral, se limita a ligeiras visitas entre parentes e amigos mais íntimos. A não serem alguns amantes da arte venatória, que procuram divertir-se em caçadas ás perdizes, codornas e outros pequenos animaes na Serra do Oiro e nos arredores da cidade, e os bilhares da Beneficência Caixeiral e os do Hotel Bahiano. Relativamente mal frequentados, só a colônia italiana se destrae em jogos e exercícios physicos nas chácaras de seus patrícios. No entanto Alagoinhas Velha se presta admiravelmente a passeios e convescotes ${ }^{4}$ bem com alguns outros pontos frescos e abundantes de água excellente (BARREIRAS, 1902, p. 202 e 203).

As ruas vazias do domingo seriam apropriadas por práticas esportivas na década posterior, porém para este momento, nos apontamentos de Américo Barreira, sua pouca utilização já nos mostra que a cidade carecia de ações que proporcionasse uma maior sociabilidade.

No período pudemos identificar a experiência com algumas práticas, não tão comuns, mas indicativas de vivências divertidas. Uma delas foi a caçada. Tal atividade nos amplia o olhar para os espaços naturais, a mata, um fenômeno que pode ser tomado como rural e assim, contraditório a uma cidade que queria ser moderna. Todavia, ao mesmo tempo, seu domínio e utilização como área de lazer demonstra uma postura mais urbana onde "o sentido do urbano contém o sentido da dominação técnica e racional sobre a natureza" (DIAS e JUNIOR, 2006, p. 2). Nesse espaço, além da caçada, ações como passeios e convescotes (lanches ao ar livre), bem mostram que as áreas verdes

\footnotetext{
${ }^{4}$ Convescotes é um neologismo feito por Dr. Castro Lopes ao referir-se sobre o que é chamado de picnic. $\mathrm{O}$ autor Américo Barreira alega no livro preferir aderir a este neologismo a optar pela ideia de estrangeirismo que o mesmo não era adepto.
} 
Lizandra de Souza Lima e Percepções Históricas sobre o Lazer e a Sociabilidade na Bahia (1850-1900) Coriolano P. da Rocha Junior

eram parte dos cenários de sociabilidade da comunidade alagoinhense (BARREIRAS, 1902).

Outra vivência de recreação eram os jogos de bilhar na cidade. Tal atividade permaneceu no cotidiano da comunidade por um longo período. Há indícios de que esse jogo de bilhar já fosse regular em diversos países como França, Inglaterra, lugares onde o ideal modernizante já era notório.

Alagoinhas, a época, contava com uma comunidade italiana. Nesta, se viam mais atividades divertidas de forma usual do que no restante da cidade, sendo por isso mesmo dissonante. Dessa forma, podemos inferir que esses costumes eram características trazidas do país natal, ou seja, ao se verem na necessidade de sair de sua pátria, a carregavam junto, na forma de experiências culturais.

Em meio as atividades que aconteciam na vimos também uma estruturação dos espaços públicos. Nesse período tivemos melhoramentos "que visava calçamento, nivelamento, abertura de ruas e construções de pontes" (LIMA, 2010, p. 108), além de abertura de praças públicas. Boa parte dessas mudanças foram executadas buscando garantir espaços de sociabilidade e comercialização, tentando dar a cidade uma estrutura mais adequada aos tempos que se projetavam. De toda forma, tais ações modernizantes, de alguma maneira, também viabilizaram ações voltadas ao entretenimento e divertimento, proporcionando espaços de lazer, sendo este, um fio condutor de experiências sociais.

Dentro deste quadro de novas experiências identificamos uma em especial, as filarmônicas e as apresentações culturais.

Na época aqui investigada havia na cidade algumas organizações musicais: 
[...] duas associações musicaes (Euterpe Alagoinhense e União Ceciliana, com duas boas philarmonicas); (...); dois clubs carnavalescos (Filhos do Sol e União Juvenil), que deram a nota mais brilhante ao Carnaval deste anno (BARREIRA, 1902, p. 195).

As praças da cidade eram palco de vários eventos da sociedade alagoinhense, como as quermesses, os festejos religiosos. As datas comemorativas como o Ano Novo e o Carnaval aproveitavam desses espaços, pois estes possuíam grande poder de concentração de pessoas. As bandas principais das filarmônicas se apresentavam nesses locais e também nos eventos de inauguração de áreas públicas. Quando da inauguração do prédio da Câmara Municipal houve um grande evento:

\begin{abstract}
Á noite esteve exposto á visita pública todo o edifício, havendo danças nos salões do concelho e do jury, tocando neste até alta madrugada a banda da União Ceciliana e naquelle dia a da Euterpe Alagoinhense; cumprindo nota que em todos os atos, não só do dia 2 , como nas noites de 3 e 4, essas duas estudiosas bandas abrilhantaram as festas com peças bem ensaiadas de seus vastos repertórios (BARREIRA, 1902, p.84).
\end{abstract}

Temos nesse perfil de eventos um padrão de lazeres que não era exclusivo de Alagoinhas. Corbin (1995) aponta que essas práticas de festividades ligadas a eventos religiosos e políticos se apresentavam como espécie de atividade de lazer para a época. Afinal, como em todo o globo, a demanda de trabalho e reorganização dos tempos e das estruturas das cidades estavam em processo de construção e a elaboração de uma cultura destinada a esses momentos ainda era frágil.

Para reger esses momentos, as duas grandes e bem-conceituadas filarmônicas (Sociedade Filarmônica Euterpe Alagoinhense e Sociedade Filarmônica União Cecíliana) ganharam visibilidade, tendo apresentações em todos os eventos de maior magnitude.

Destas duas identificadas, primeiro surgiu a União Cecíliana, em 1883 e dez anos depois a Euterpe Alagoinhense. Ambas participavam das ações e eventos que 
Lizandra de Souza Lima e Percepções Históricas sobre o Lazer e a Sociabilidade na Bahia (1850-1900) Coriolano P. da Rocha Junior

haviam na cidade. Desde a inauguração da Estrada de Ferro, até os eventos religiosos, como as quermesses organizadas pela igreja.

Além destes encontros musicais, ainda existiam as micaretas que ocorriam na cidade no período do Carnaval. Elas agitavam a vida social no período e também o próprio comércio da cidade, que passava a vender novos produtos, graças aos festejos. Joanita Santos (1987), narra esse momento como uma ocasião bastante eclética em um contexto público. Em seus relatos, ela descreve as brincadeiras que ocorriam durante a festa, Dentre elas cita um produto vendido pelo boticário da cidade: uma bola de água de cheiro colorida. As pessoas costumavam lançar essas bolas perfumadas umas nas outras, tingindo as roupas e provocando alvoroço entre os que passavam (SANTOS 1987).

Ao som das filarmônicas e também dos clubes carnavalescos Filhos do Sol, União Juvenil e Cavalheiros de Veneza (este último criado por cidadãos de origem italiana), a população de Alagoinhas usufruía deste momento para confraternizar e socializar entre si (LIMA, 2010).

\section{Ações de Lazer e Sociabilidade no Final do Século XIX}

O sentido de cidade perpassa a ideia de uma organização de espaço geográfico, lugar de produção e do comércio e voltado ao individualismo (DORTIER, 2010). Para lidar com esse novo padrão social, a comunidade organiza ações e locais que promovam a sociabilidade perdida, porém, a mesma precisa ser repaginada e reestruturada para o olhar da modernidade. Na história de Alagoinhas, partindo da sua emancipação, vemos como práticas sociais de lazer, atividades como o teatro, as filarmônicas e os espaços públicos como as praças, por exemplo. 
Lizandra de Souza Lima e Percepções Históricas sobre o Lazer e a Sociabilidade na Bahia (1850-1900) Coriolano P. da Rocha Junior

Vamos acompanhar a seguir a configuração de cada um desses espaços e práticas, a fim de apontar quais ações culturais eram organizadas nesses lugares.

\section{O teatro e sociedade}

As primeiras movimentações artísticas da sociedade podem ser acompanhadas a partir das edições dos jornais $A$ verdade. Neste, encontramos os relatos de apresentações teatrais que ocorriam sob organização da Família Granado e da Sociedade 7 de Setembro. Apesar das poucas edições preservadas deste boletim, é possível perceber que a prática era tradicional, embora não tenhamos conseguido identificar se ocorria periodicamente ou ao menos, o local exato onde se passava, porém, é certo dizer que chamava a atenção da população, seja pelo tema ou pela própria arte em si.

Na edição do Jornal $A$ verdade de 2 de julho de 1877, foi noticiada um ato, com um enredo em tom cômico abordando a cultura cigana e a militar. A peça em questão foi intitulada de $A$ cigana e o soldado e foi apresentada pela imprensa com uma baixa aceitação da população, devido ao fato de "atenuar qualquer mente que por ventura exerce aquela composição, a dificuldade natural em apreciar devidamente o jogo de palavras em língua diversa da que fala a população".

Ao mesmo tempo em que essas limitações poderiam apresentar-se nas composições teatrais, é possível observar que elas não eram impeditivas para suas práticas, já que vemos outros relatos de apresentações no mesmo contexto.

A sociedade 7 de Setembro, pelo que consta no $A$ Verdade, de 11 de fevereiro de 1877, tinha um perfil de organizar peças teatrais, buscando atender causas beneficentes. Nessa edição há uma descrição de uma peça voltada ao levantamento de fundos para a 
Lizandra de Souza Lima e Percepções Históricas sobre o Lazer e a Sociabilidade na Bahia (1850-1900) Coriolano P. da Rocha Junior

alforria de uma escrava, porém a apresentação não logrou o mesmo êxito da organizada pela Família Granado.

Em 1877, o país já beirava um período que traria significativas mudanças em seu sistema econômico, havia o debate sobre a abolição da escravatura e também se viam as reverberações da revolução industrial, que implicariam em adequações dos padrões de consumo, de comportamentos, e econômicos. Essa mudança processual não era uma ação amplamente aceita pela sociedade, pois o novo acaba muitas das vezes por causar estranheza, por mais que ele seja desejado, essa é uma das ambiguidades da modernidade.

Nessa mesma edição (7 de setembro de 1877) há a divulgação da próxima peça a ser apresentada pela Sociedade, que aconteceria no mês seguinte, dessa vez em prol das vítimas de uma inundação que ocorrera em Portugal. Sobre esta o redator expõe "É de crer que n'aquele dia fique repleto o theatro, pois que a caridade não conhece nacionalidades nem tem limites sua expansão".

No ano seguinte, em 1878, na edição de 29 de maio do Jornal O Porvir temos relatos de apresentações theatrais, porém sem tantos detalhes sobre tema ou organização do ato, mas ainda assim há comentários de incentivo à adesão dos telespectadores do evento.

É possível visualizar assim que a iniciativa teatral além de regular, já que se apresenta em diversas edições e jornais diferentes, era emblemática na sociedade, pois, além de apresentar à recente cidade uma cultura artística, também aproximava a comunidade de temas relevantes à época ou a culturas recém-chegadas, como no caso das apresentações culturais da Família Granado. 
Lizandra de Souza Lima e Percepções Históricas sobre o Lazer e a Sociabilidade na Bahia (1850-1900) Coriolano P. da Rocha Junior

Apesar de não noticiadas nos folhetins locais, a Família Granado, na figura de Maria Granado, era envolvida tradicionalmente em ações culturais. No jornal $A$ Notícia, que circulava na capital, há notas sobre as apresentações de dança realizadas pela mesma e por seu par Ernesto Navarro. Na capital, Salvador, as apresentações eram regulares, tendo notas em edições variadas. Como a família promovia ações em Alagoinhas, e pela escassez de fonte do período que compreende o final do século XIX é possível que tenham ocorrido ainda mais ações culturais voltadas ao teatro e a dança do que tivemos acesso.

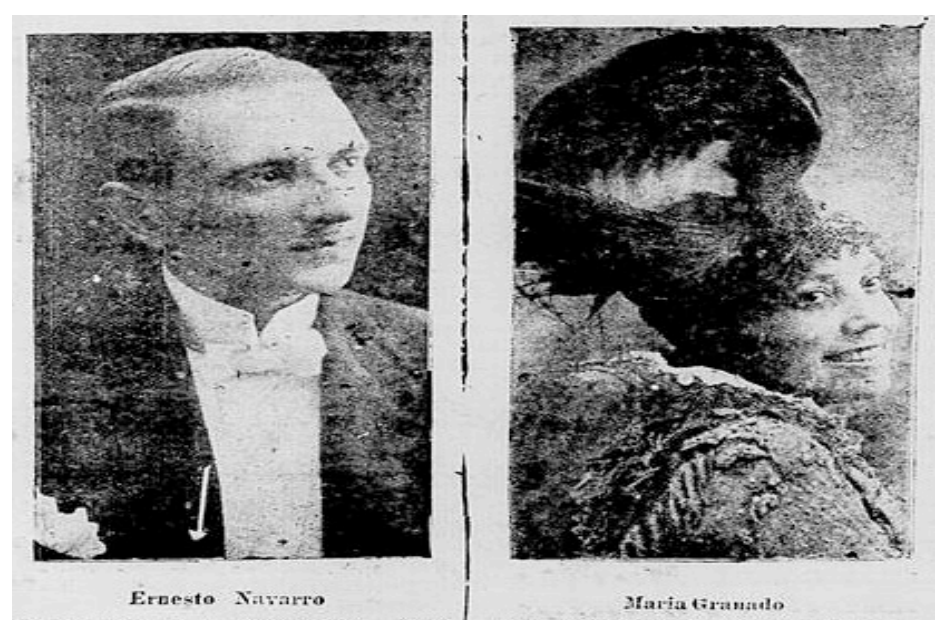

Fonte: A Notícia, edição 117, 1915.

Entendendo que, em suma, a composição do público expectador é determinante para a execução e concretização de ações teatrais, temos nessa prática uma iniciativa de sociabilidade efetiva para época que além de ter uma ação ativa no momento da exibição da mesma, ainda repercutia na sociedade como assunto de discussões tendo em vista que as peças compunham as notas dos jornais do período.

Porém a apropriação da mesma pelo público tornava-se limitada possivelmente devido ao estranhamento à linguagem utilizada pelos atores, como citado nas notas dos folhetins. Ainda é notório ressaltar que no período tínhamos uma crescente da 
Lizandra de Souza Lima e Percepções Históricas sobre o Lazer e a Sociabilidade na Bahia (1850-1900) Coriolano P. da Rocha Junior

população negra e alforriada, que não contava com capital financeiro para a apropriação desses espaços, e quando o mesmo ocorria em espaço público provavelmente a total compreensão da discussão ficava debilitada, devido a pouco acesso aos estudos.

\section{As Filarmônicas e Iniciativas Musicais: Da Estrutura às Práticas}

A década seguinte, de 1880 a 1889, é marcada por uma nova ação cultural: as filarmônicas. Como vimos, no início desde período, no ano de 1883 foi fundada a " 1 a Banda Musical com o nome "Sociedade Beneficente União Cecíliana”, por Robato João e sob a regência de Honório Marques" (BARROS, 1979, p. 51).

Nos versos da memorialista e poetisa Joanita Santos vemos a dimensão do envolvimento da cidade com as ações das filarmônicas. Dentre as iniciativas de lazer registradas na época é possível observar que estas instituições promoviam a maior parte das atividades aderidas pela população.

A partir dessa iniciativa temos um grande marco nos investimentos de lazer na província. A apropriação da arte musical, para além dos momentos paroquiais, trazia pra vila uma nova cultura: a música. $O$ investimento na arte musical que chegara a Alagoinhas no final do século XIX já fazia parte da realidade brasileira desde o início do século, com a chegada da Família Real. Corrêa afirma que "A música era a arte preferida da corte e muito se gastava anualmente com a manutenção da Capela Real e seu corpo de artistas, composto por muitos cantores (2013, p. 15)”.

O ingresso da Família Real no Brasil trouxe uma variedade de costumes para o país, mas, além disso, também ampliou o acesso dos imigrantes europeus à essas terras. Na Bahia, no período de 1864 chegaram um total de 4.130 imigrantes tendo nesse montante, em ordem de quantidade, portugueses, italianos, ingleses, alemães e 
Lizandra de Souza Lima e Percepções Históricas sobre o Lazer e a Sociabilidade na Bahia (1850-1900) Coriolano P. da Rocha Junior

franceses. Boa parte desses italianos foi enviada para a construção das estradas de ferro do estado (BENEDINI, 2013).

Em Alagoinhas, eles mantiveram o padrão dos estrangeiros chegados ao estado na época: "os poucos estrangeiros dotados de algum capital preferiram investir em outras atividades, como o artesanato e o comércio, enquanto os demais buscavam um salário nas raríssimas, porém seguras, atividades industriais (BENEDINI, 2013, p. 3)”.

A cultura europeia, já apropriada das bandas musicais, chegando ao Brasil, reacendeu as iniciativas culturais ligadas a essa arte. Logo, o que começou compondo eventos sociais passava agora a configurar sua própria cena. Tínhamos um determinado público que, vindo da capital através do trem, trazia a Vila novos conceitos e interpretações de consumo e uso do seu tempo livre. Eles excitavam a população com tendências de uma modernidade que os Alagoinhenses almejavam.

As filarmônicas não lograram êxito imediato com sua chegada. A Sociedade Beneficente Philarmônicas União Ceciliana e a Philarmônica Orphesina acabaram entrando em falência (LIMA, 2010). É relevante salientar que este foi um período onde todo o país sofreu uma crise econômica proveniente da consolidação da república. Era um momento delicado para o país e também para a recém-cidade de Alagoinhas.

De toda forma, esse cenário só foi reconfigurado em 1893 com a "Fundação da Sociedade Filarmônica Euterpe Alagoinhense. (...) Os Estatutos Sociais foram elaborados em 1899, por Benevides Macedo Silva, Mares de Souza e Eustórgio Velloso (BARROS, 1979, p. 53)". A Sociedade Philarmônica União Ceciliana retornou ao cenário cultural da cidade em 1908, reformulada, porém sem a mesma estrutura já construída pela Euterpe, que desde seu início já tinha sua própria sede o "Clube Social da Euterpe - um velho sobrado cheio de sacadas e com várias janelas protegidas por 
Lizandra de Souza Lima e Percepções Históricas sobre o Lazer e a Sociabilidade na Bahia (1850-1900) Coriolano P. da Rocha Junior

grades artisticamente trabalhadas que se localizava (...) na antiga Rua da Câmara (LIMA, 2010, p.113)”.

Desde a fundação as Philarmônicas da Euterpe e União Ceciliana se apresentavam em todos os eventos da cidade, fossem eles políticos ou religiosos. Participando da inauguração da sede da Câmara Municipal, por exemplo, assim como das quermesses e festejos das missas realizadas no largo a frente da Igreja Matriz, a beira dos trilhos do trem.

Além das filarmônicas, o cenário cultural musical da cidade também envolvia os clubes carnavalescos da cidade. Organizados em 1901 dentre estes clubes vemos os "Filhos do Sol, União Juvenil e Cavalheiros de Veneza, sendo seus fundadores os cidadãos de nacionalidade italiana residentes na cidade e ainda uma ala moça de alagoinhenses, apresentando-se ao público até o ano de 1910”. (BARROS, 1979, p. 54).

Sobre a organização desses clubes carnavalescos não há muitos registros do período do nosso recorte temporal, sabemos apenas que se estruturaram nesse momento, porém não encontramos edições de periódicos que relatassem mais detalhes sobre suas ações.

\section{Os Espaços Públicos e suas Práticas Sociais}

A construção dos espaços públicos ilustram as ações voltadas ao lazer e a sociabilidade, sejam ela por iniciativa governamental ou não. A finalidade aqui é analisar a composição e utilização dos espaços públicos onde aconteciam as práticas sociais de lazer independente deles apresentarem estrutura adequada para isto. Nesse âmbito teremos as praças e seus coretos voltados às apresentações musicais, assim como o espaço de feira onde historicamente ocorria ações socioculturais. 
Lizandra de Souza Lima e Percepções Históricas sobre o Lazer e a Sociabilidade na Bahia (1850-1900) Coriolano P. da Rocha Junior

Como já citado, o primeiro espaço público a ter atuação na sociabilidade da comunidade foi o largo da igreja do vilarejo na primeira sede da cidade, na ainda Freguesia de Santo Antônio das Alagoinhas. As feiras e as ações da igreja, como as missas festivas e as quermesses, levavam a comunidade um ambiente de entretenimento que fomentava o divertimento da população local.

Boa parte desta animação dava-se a aglomeração de pessoas devido a comercialização dos produtos. Tínhamos desde os feirantes e mascates passando pelos consumidores dos serviços e uma gama de frequentadores que iam a este espaço apenas para usufruir do mesmo como espaço de divertimento, o que desencadeava por diversas vezes a situações de conflito e desentendimentos devido a ação destes que eram entendidos como "arruaceiros" para os demais moradores da localidade.

Com a chegada dos trilhos férreos e o abandono desse ambiente primário, temos a estruturação de novos espaços. A feira ainda permanecia tão diversa quanto antes, porém a normatização legal do ordenamento espacial e comportamental dos frequentadores levava a esse ambiente uma espécie de desintegração cultural.

Em contrapartida, nessa nova localidade, tivemos investimentos nas aberturas de praças que fomentariam a sociabilidade na região. Temos como exemplos destas construções: a Praça do Comercio, que teve sua construção iniciada já em 1863, seguido em 1869 da Praça do Cruzeiro, em 1884 a inauguração do Mercado Público Municipal; ambientes que abrigavam encontros e apresentações culturais de diversas frentes, mesmo que sem uma organização frequente.

A população que utilizava desses espaços apenas a fim de comercio era surpreendida, por vezes, com as ações culturais relatadas nos tópicos anteriores. Exceto em datas comemorativas, quando da inauguração dos recintos, ou quando da 
Lizandra de Souza Lima e Percepções Históricas sobre o Lazer e a Sociabilidade na Bahia (1850-1900) Coriolano P. da Rocha Junior

comemoração ligada a datas políticas, onde tanto a iniciativa privada quanto governamental ornava esses lugares para festejos e apresentações, muitas vezes das filarmônicas.

\section{Considerações Finais}

Vemos a partir desse levantamento que as práticas de lazer e sociabilidade do século XIX se estruturaram em Alagoinhas, assim como em todo o país, a partir da interação ideológica e cultural entre a população nacional e a chegada estrangeira, sob a bandeira da modernidade e do desenvolvimento.

Com a nova estrutura econômica e o ingresso de capital estrangeiro, vimos em Alagoinhas a influencia do povo imigrante na organização dos produtos de comercio e na cultura de entretenimento local.

No tocante dos entretenimentos, duas atividades tiveram destaque reforçado pelas produções acadêmicas e literárias, as bandas filarmônicas e o teatro, ambas fomentadas por descendentes dos italianos e espanhóis que tiveram sua chegada facilitada pela conjuntura da implantação da linha férrea inglesa.

A cidade de Alagoinhas passava nesse momento por sua estruturação urbana e, dessa forma, todo ordenamento do centro urbano se deu visando os ideais trazidos por essa nova realidade nacional, a ligação intermunicipal através da estrada férrea.

É notório que o processo de crescimento urbano e demográfico da cidade, aliado as concepções trazidas pelo ideal de modernidade, como o individualismo e do ambiente privado, fez com que sua nova sede necessitasse de um maior cuidado com os espaços comuns e as ações que promovessem a sociabilidade integrando a esses espaços também as práticas culturais nos momentos de lazer. 
Porém, mesmo com um espaço ordenado para a vivencia em grupo, boa parte das ações de entretenimento ocorriam dentro de momentos que não eram de fato livre para a maioria da sociedade. Enquanto uma parcela ia as feiras para realizar compras de mantimentos outra gama de pessoas ia para esse espaço numa vertente laboral, como as mucamas e as damas de companhia, assim como os próprios feirantes e estes apesar atuarem no mesmo ambiente, não teriam como usufruir das ações culturais que ocorriam no dado momento.

Lidar com o lazer é lidar com tensões sociais atreladas a sua prática. Afinal, o direito ao lazer é algo conquistado em luta e não adquirido de livre ação e isso não se apresenta diferente na história da cidade de Alagoinhas. Como cidade do interior do estado da Bahia, é possível observar que a tentativa de acompanhar o crescimento econômico nacional não tangia em primeira ordem a atenção ao direito de lazer. Contudo, a modernidade defendia a vivencia em comunidade, logo a sociabilidade, espaço primário do que nos é licito e livre, nesse momento histórico, abriga em si os primórdios do que viria a compor o lazer no século seguinte.

\section{REFERÊNCIAS}

Alagoinhas. Secretaria de Educação e Cultura. Prefeitura Municipal de Alagoinhas. 1996.

Jornal A verdade. 11 de fev. 1877. Disponível em:

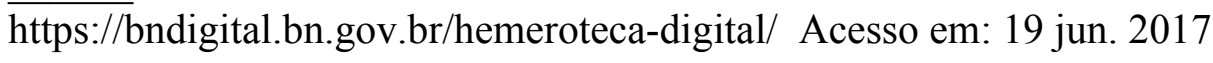

Jornal A verdade. 2 de jul. 1877. Disponível em: https://bndigital.bn.gov.br/hemeroteca-digital/ Acesso em: 19 jun. 2017

Jornal A verdade. 31 de mar. 1878. Disponível em: http://bndigital.bn.gov.br/hemeroteca-digital/ Acesso em: 19 jun. 2017

Jornal A verdade. 1 de abr. 1882. Disponível em:

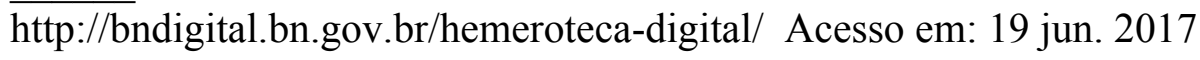


Lizandra de Souza Lima e Percepções Históricas sobre o Lazer e a Sociabilidade na Bahia (1850-1900) Coriolano P. da Rocha Junior

. Jornal A voz do povo. 16 de jul. 1881. Disponível em:

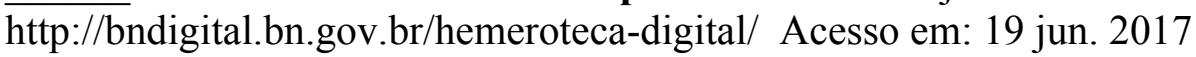

Jornal O Alagoinhense. 14 de jun. 1885. Disponível em:

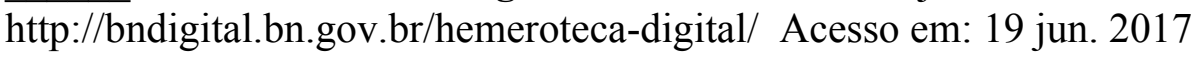

ALAGOINHAS. Jornal O Porvir. 20 de mai. 1878. Disponível em: http://bndigital.bn.gov.br/hemeroteca-digital/ Acesso em: 19 jun. 2017

ARAÚJO, M. M. S. O papel da cidade de Alagoinhas na centralidade e articulação espacial urbana da Região Litoral Norte da Bahia. Campinas - SP, 2010. Disponível em: http://www.abep.nepo.unicamp.br/encontro2010/docs_pdf/ eixo_1/abep2010_2040.pdf Acesso em: 20 jun. 2017.

BARREIRA, A. Alagoinhas e seu município: Notas e Apontamentos para o futuro. Typografia D' O Popular. Alagoinhas, 1902.

BARROS, S. Vultos e Feitos do município de Alagoinhas, 1979.

BENEDINI, G.F. A emigração italiana para a Bahia. Fênix - Revista de História e Estudos Culturais, v. 10, n. 2, p. 1-20. Julho - Dezembro de 2013. Disponível em: http://www.revistafenix.pro.br/PDF32/ARTIGO_10_SECAO_LIVRE_

GIUSEPPE_FEDERICO_BENEDINI_FENIX_JUL_DEZ_2013.pdf Acesso em 10 jul. 2017

BOLELLI, R. O Brasil na segunda metade do século xix: mudanças econômicas, o comércio internacional e a problemática do padrão ouro. $65^{\mathrm{a}}$ Reunião anual da SBPC, Universidade Federal de Pernambuco, jul. 2013. Disponível em: www.sbpcnet.org.br/livro/65ra/resumos/resumos/3685.html . Acesso em: 20 jun. 2017.

BULHÕES, A. M. de O. Estudos definitivos de Alagoinhas ao Joazeiro e Casa Nova. Thypografia de G. Leuzinger \& Filhos, 1874.

CARDOZO, J. M. C. Poder e hegemonia na construção do conhecimento do Lazer. In: ISAYAMA, H. F.; OLIVEIRA, M. A. (Org.) Produção de conhecimento em Estudos do Lazer. Belo Horizonte: Editora UFMG, 2014.

CORRÊA, C. G. O desenvolvimento cultural, artístico e a moda no Brasil após a chegada da corte portuguesa. (Monografia) Instituto de Artes e Design da Universidade de Juiz de Fora. Minas Gerais, 2013.

CORBIN, Alain: História dos tempos livres. Lisboa: Teorema, 1995.

DIAS, C. A. G.; JUNIOR, E. de D. A. Esporte, cidade e natureza: um estudo de caso. Instituto Virtual do Esporte, n. 28, nov. 2006. Centro de Memória Inezil Penna Marinho. Disponível em: http://www.ceme.eefd.ufrj.br/ive/boletim/bive200611/ noticias/Esporte\%20na\%20natureza\%20Licere.pdf Acesso em: 20 jun. 2017.

DORTIER, J. Dicionário de Ciências Humanas. Revisão e coordenação da tradução Maria Valeria Martinez de Aguiar - São Paulo: Editora WWF Martins Fontes, 2010. 
DUMAZEDIER, J. Lazer e Cultura Popular. 4. ed. São Paulo: Editora Perspectiva, 2014.

FREIRE, A. L. O.; SARTORIO, F. D. Urbanização e Lazer: Aspectos do processo histórico da criação de espaços públicos em Vitória (ES). Revista do Programa de Pós-Graduação em Geografia UFES, p. 42 - 57. Jan/Jul. 2015

GONÇALVES, C.; MELO, V. A. Lazer e Urbanização no Brasil: notas de uma história recente (décadas de 1950/1970). Porto Alegre - RS. Revista Movimento, v. 15, n 3, p. 249-271, jul./set., 2009.

LIMA, K. M ${ }^{a}$ S. do N. Entre a ferrovia e o comércio: urbanização e vida urbana em Alagoinhas (1868 - 1929). Dissertação (Mestrado) História da Universidade Federal da Bahia, Salvador-BA, 2010.

MELO, V. A.; ALVES Jr., E. de D. Introdução ao Lazer. 2. ed. Barueri: Editora Manole, 2012.

MELO, Victor Andrade de et al. Pesquisa histórica e história do esporte. Rio de Janeiro, 7 letras, 2013.

MORIN, E. Cultura de Massas no século XX. O espirito do tempo - 1 Neurose. 9. ed. Rio de Janeiro: Forense Universitária, 1997.

SANTANA, A. H. G. de. Conflitos pela propriedade e reordenamento do trabalho em Alagoinhas e Inhambupe (1860 - 1890). Dissertação (Mestrado). Universidade Federal Rural do Rio de Janeiro, Rio de Janeiro, 2015.

SANTOS, J. C. Traços de Ontem. 1987.

SANTOS, L. C. R. Dos. A igreja inacabada e a estação ferroviária: recompondo a memória de alagoinhas. In: ENECULT - ENCONTRO DE ESTUDOS MULTIDISCIPLINARES EM CULTURA, Salvador, 5 - BA, maio de 2009. Disponível em: http://www.cult.ufba.br/ enecult2009/19184.pdf .Acesso em: 19 jun. 2017.

\section{Endereço dos Autores:}

Lizandra de Souza Lima

Avenida Ayrton Senna da Silva, 615/ap.402-Bloco 18

Alagoinhas - BA - 48.030-640

Endereço Eletrônico: lizandralima@live.com

Coriolano P. da Rocha Junior

Rua Alagoinhas, 489/504A - Rio Vermelho

Salvador - BA - 41.940-620

Endereço Eletrônico: coriolanojunior@uol.com.br 